\title{
Trichoderma reesei FS10-C enhances phytoremediation of Cd-contaminated soil by Sedum plumbizincicola and associated soil microbial activities
}

\author{
Ying Teng *, Yang Luo, Wenting Ma, Lingjia Zhu, Wenjie Ren, Yongming Luo, \\ Peter Christie and Zhengao $\mathrm{Li}$
}

Key Laboratory of Soil Environment and Pollution Remediation, Institute of Soil Science, Chinese Academy of Sciences, Nanjing, China

OPEN ACCESS

Edited by:

Ying Ma,

University of Coimbra, Portugal

Reviewed by:

Igor Kovalchuk,

University of Lethbridge, Canada

Jacek Kozdrój,

University of Agriculture in Krakow,

Poland

*Correspondence:

Ying Teng,

Key Laboratory of Soil Environment and Pollution Remediation, Institute of Soil Science, Chinese Academy of Sciences, 71 East Beijing Road,

Nanjing 210008, China

yteng@issas.ac.cn

Specialty section:

This article was submitted to

Plant-Microbe Interaction,

a section of the journal

Frontiers in Plant Science

Received: 05 December 2014

Accepted: 28 May 2015

Published: 10 June 2015

Citation:

Teng Y, Luo Y, Ma W, Zhu L, Ren W

Luo Y, Christie P and Li Z (2015)

Trichoderma reesei FS10-C enhances

phytoremediation of $\mathrm{Cd}$-contaminated

soil by Sedum plumbizincicola and associated soil microbial

activities

Front. Plant Sci. 6:438. doi: 10.3389/fp/s.2015.00438
This study aimed to explore the effects of Trichoderma reesei FS10-C on the phytoremediation of Cd-contaminated soil by the hyperaccumulator Sedum plumbizincicola and on soil fertility. The Cd tolerance of T. reesei FS10-C was characterized and then a pot experiment was conducted to investigate the growth and Cd uptake of S. plumbizincicola with the addition of inoculation agents in the presence and absence of $T$. reesei FS10-C. The results indicated that FS10-C possessed high Cd resistance (up to $300 \mathrm{mg} \mathrm{L}^{-1}$ ). All inoculation agents investigated enhanced plant shoot biomass by $6-53 \%$ of fresh weight and $16-61 \%$ of dry weight and $\mathrm{Cd}$ uptake by the shoots by $10-53 \%$ compared with the control. All inoculation agents also played critical roles in increasing soil microbial biomass and microbial activities (such as biomass $\mathrm{C}$, dehydrogenase activity and fluorescein diacetate hydrolysis activity). Two inoculation agents accompanied by FS10-C were also superior to the inoculation agents, indicating that T. reesei FS10-C was effective in enhancing both $\mathrm{Cd}$ phytoremediation by S. plumbizincicola and soil fertility. Furthermore, solid fermentation powder of FS10-C showed the greatest capacity to enhance plant growth, Cd uptake, nutrient release, microbial biomass and activities, as indicated by its superior ability to promote colonization by Trichoderma. The solid fermentation powder of FS10-C might serve as a suitable inoculation agent for $T$. reesei FS10-C to enhance both the phytoremediation efficiency of $\mathrm{Cd}$-contaminated soil and soil fertility.

Keywords: Trichoderma reesei FS10-C, cadmium, phytoremediation, Sedum plumbizincicola, soil microbial activities

\section{Introduction}

Soil contamination by heavy metals (HMs) such as cadmium released from agricultural and industrial activities is an environmental problem worldwide. Potentially toxic HMs are resistant to biodegradation and their persistence thus threatens the environment and public health (Lima et al., 2011; Sahu et al., 2012). A number of methods have been developed for the remediation of metal-contaminated soils and phytoremediation is considered to be a promising technique 
because it is cost-effective and environmentally friendly. However, its use in field conditions has been somewhat restricted (Li et al., 2011; Shin et al., 2012; Wu et al., 2012).

In recent years plant-associated bacteria and fungi have been examined for their capacity to enhance the efficiency of phytoremediation (Rajkumar et al., 2012). Numerous filamentous fungi such as Trichoderma sp. have aroused increasing interest due to their potential for enhancing the establishment of vegetation and the remediation of metalcontaminated soils (Bareen et al., 2012). Moreover, Trichoderma species are characterized by rapid growth, asexual reproduction, effective colonization capacity and low-specificity plant symbiosis (Williams et al., 2003; Harman et al., 2004; Zafar et al., 2007). Certain Trichoderma species have been reported to enhance plant growth and metal availability to plants in contaminated soils. Babu et al. (2014b) reported that Trichoderma virens PDR-28 increased the dry biomass of maize and its $\mathrm{Cd}$ accumulation compared with the control. Similarly, T. pseudokoningii increased the biomass and $\mathrm{Cd}$ accumulation of pearl millet (Bareen et al., 2012). However, little is known about the effects of $T$. reesei on the phytoremediation of $\mathrm{HM}$ contaminated soils.

The objectives of the present study were to explore the effects of Trichoderma reesei FS10-C (isolated and preserved previously in our laboratory) on $\mathrm{Cd}$ phytoremediation by Sedum plumbizincicola, a Cd hyperaccumulator (Wu et al., 2012; Hu et al., 2013), to evaluate soil fertility after phytoremediation, mainly based on microbial biomass and activities, and to determine the colonization ability of Trichoderma.

\section{Materials and Methods}

\section{Cd Tolerance and Morphological Analysis of Trichoderma reesei FS10-C}

The Cd tolerance of FS10-C was examined by incubation at $28^{\circ} \mathrm{C}$ on Potato Dextrose agar (PDA; Tapia et al., 2011) and in corresponding liquid media containing $0,5,10,15,50,100$, 150, 200, 250, and $300 \mathrm{mg} \mathrm{L}^{-1} \mathrm{Cd}^{2+}\left(\mathrm{CdCl}_{2} \cdot 2.5 \mathrm{H}_{2} \mathrm{O}\right)$. Colony diameters were measured after growth for 3 days. Mycelia in the conical flasks were collected after 5 days and then dried at $70^{\circ} \mathrm{C}$ for $24 \mathrm{~h}$ before being weighed. Furthermore, the $\mathrm{EC}_{50}$ of FS10-C under Cd stress was calculated by the linear interpolation method (Hughes et al., 2001).

The morphological changes in FS10-C under Cd stress were studied by incubating the activated strain in Potato Dextrose (PD) media at $28^{\circ} \mathrm{C}$ and at $150 \mathrm{rev} \min ^{-1}$ for 5 days. Equal amounts of mycelia were picked off and added to Czapek's medium (Kexiang et al., 2002) spiked with 0, 10, and $100 \mathrm{mg} \mathrm{L}^{-1} \mathrm{Cd}^{2+}\left(\mathrm{CdCl}_{2} \cdot 2.5 \mathrm{H}_{2} \mathrm{O}\right)$ respectively for further incubation for $15 \mathrm{~h}$ at $28^{\circ} \mathrm{C}$ and at $150 \mathrm{rev} \mathrm{m^{-1 }}{ }^{-}$A moderate amount of mycelium was then extracted, immobilized with $4 \%$ glutaraldehyde solution prepared using $0.2 \mathrm{~mol} \mathrm{~L}^{-1}$ phosphate buffered saline (PBS, $\mathrm{pH}$ 7.2) for $4 \mathrm{~h}$, and washed with $0.1 \mathrm{~mol}$ $\mathrm{L}^{-1} \mathrm{PBS}(\mathrm{pH}$ 7.2) three times. After ethanol dehydration, the ethanol was replaced twice with isoamylacetate, for $15 \mathrm{~min}$ each time. Finally, electrical conductivity (15 mA, $90 \mathrm{~s})$ was measured after critical point drying. Treated samples were then observed with a scanning electron microscope (SEM, FEI Quanta 200, Hillsboro, OR, USA) and evaluated qualitatively and quantitatively with an Energy Dispersive X-ray Detector (EDX, INCA E-250, High Wycombe, UK).

\section{Preparation of Inoculation Agents}

To apply Trichoderma sp. widely in practice the first task is to obtain a large number of Trichoderma products. Thus far, the Trichoderma agents produced in commercial applications have been intended primarily for spore preparation. In this context, we prepared several inoculation agents using the following preparation methods. The fermentation conditions and proportion parameters were explored in orthogonal experiments.

Trichoderma reesei FS10-C was first activated in PDA media and then prepared as a spore suspension $\left(1 \times 10^{6}\right.$ colonyforming units $\left.\mathrm{mL}^{-1}\right)$. The spore suspension was inoculated onto a sterilized solid matrix $(1: 20 \mathrm{v} / \mathrm{w})$ and incubated at $28^{\circ} \mathrm{C}$ for 10 days. The solid matrix consisted of orange peel powder and wheat bran $(1: 1 \mathrm{w} / \mathrm{w})$ with the moisture content adjusted to $50 \% \mathrm{w} / \mathrm{v}$ using deionized water. This fermented product was designated 'solid fermentation powder of T. reesei FS10-C' and its efficacy was examined with and without sterilization (the first and second inoculation agents).

Conidium wettable powder of T. reesei FS10-C was the third inoculation agent, consisting of a mixture of $10 \% T$. reesei FS10-C conidium powder, 5\% sodium dodecyl benzene sulfonic acid, $0.4 \%$ vitamin $\mathrm{C}, 10 \%$ kaolinite and $74.6 \%$ sodium lignosulphonate. This mixture, without the addition of $10 \%$ T. reesei FS10-C conidium powder, was used as the fourth inoculation agent. These latter two inoculation agents were diluted 500 times before use.

\section{Sample Collection and Experimental Design}

Soil samples were collected from the arable layer (top $15 \mathrm{~cm}$ ) of a Cd-contaminated agricultural soil located in Xiangtan, Hunan Province, China. The physicochemical properties and Cd content of the soil samples are shown in Table 1. The soil was air dried, sieved ( $2 \mathrm{~mm})$, and mixed thoroughly with $0.15 \mathrm{~g} \mathrm{~kg}^{-1} \mathrm{~N}$ as $\left(\mathrm{NH}_{4}\right)_{2} \mathrm{SO}_{4}, 0.20 \mathrm{~g} \mathrm{~kg}^{-1} \mathrm{P}$ as $\mathrm{NaH}_{2} \mathrm{PO}_{4}$

TABLE 1 | Selected physicochemical properties of the soil used in the pot experiment.

\begin{tabular}{|c|c|}
\hline Soil property & Value \\
\hline $\mathrm{pH}\left(\mathrm{H}_{2} \mathrm{O}\right)$ & 4.7 \\
\hline Organic matter $\left(\mathrm{g} \mathrm{kg}^{-1}\right)$ & 32.0 \\
\hline Total $\mathrm{N}\left(\mathrm{g} \mathrm{kg}^{-1}\right)$ & 2.2 \\
\hline Total P $\left(\mathrm{g} \mathrm{kg}^{-1}\right)$ & 0.5 \\
\hline Total K $\left(\mathrm{g} \mathrm{kg}^{-1}\right)$ & 11.2 \\
\hline Hydrolyzable nitrogen $\left(\mathrm{mg} \mathrm{kg}^{-1}\right)$ & 91.0 \\
\hline Available $\mathrm{P}\left(\mathrm{mg} \mathrm{kg}^{-1}\right)$ & 8.6 \\
\hline Available $\mathrm{K}\left(\mathrm{mg} \mathrm{kg}^{-1}\right)$ & 55.0 \\
\hline $\mathrm{Cd}\left(\mathrm{mg} \mathrm{kg}^{-1}\right)$ & 0.53 \\
\hline
\end{tabular}


and $0.30 \mathrm{~g} \mathrm{~kg}^{-1} \mathrm{~K}$ as $\mathrm{KCl}$. Seedlings of S. plumbizincicola were obtained from a heavy-metal polluted area in Zhejiang Province, east China and were $\sim 5 \mathrm{~cm}$ long with a pair of leaves and 4-5 nodes. Healthy plants of uniform size were chosen for the pot experiment after the seedlings had produced roots under incubation in half-strength Hoagland nutrient solution for 2 weeks.

In the pot experiment five treatments were set up in a fully randomized layout, namely: (1) uninoculated S. plumbizincicola as control (CK); (2) S. plumbizincicola inoculated with solid fermentation powder of $T$. reesei FS10-C (SP); (3) S. plumbizincicola inoculated with sterilized solid fermentation powder (SCK); (4) S. plumbizincicola inoculated with conidium wettable powder of T. reesei FS10-C (WP); (5) S. plumbizincicola inoculated with conidium wettable powder without the addition of $T$. reesei FS10-C conidia (WCK). The inoculation method for the SP and SCP treatments was hole fertilization ( $4 \%$ inoculum was added), whereas spray irrigation (100 mL per pot was added at $0,30,60,90$, and 120 days respectively) was used for the WP and WCP treatments. Each treatment was set up in quadruplicate, giving a total of 20 pots. Each pot received $1.5 \mathrm{~kg}$ soil and five plants.

The plants grew in a growth chamber under controlled light (14-h photoperiod at $\left.1.5 \times 10^{4} \mathrm{lux}\right)$, temperature $\left(25 / 20^{\circ} \mathrm{C}\right.$, light/dark), and humidity (60-70\%). Throughout the experiment the plants were watered with deionized water to maintain $70 \%$ of water-holding capacity. Shoot and soil samples were collected after incubation for 120 days. Shoot fresh and oven dry weights (DWs) were determined. A portion of the soil samples was airdried, ground and sieved $(0.15 \mathrm{~mm})$ before analysis for $\mathrm{pH}$ and available phosphorus (P). Soil $\mathrm{pH}$ was measured using a $\mathrm{pH}$ meter (520M-01, Thermo Orion, Beverly, MA, USA) and soil available $P$ was determined based on the Olsen method (Olsen et al., 1954). The remaining potion of the soil samples was sieved $(<2 \mathrm{~mm})$ for subsequent experiments.

\section{Analysis of Cd in Soil and Plant Samples}

Ground plant samples weighing $0.5 \mathrm{~g}$ were placed into digestion vials and mixed with $10 \mathrm{~mL}$ of $\mathrm{HClO}_{4}: \mathrm{HNO}_{3}(2: 3 \mathrm{v} / \mathrm{v})$. Dry soil samples $(0.25 \mathrm{~g})$ were weighed and mixed with $14 \mathrm{~mL}$ of $\mathrm{HCl}: \mathrm{HNO}_{3}(4: 1 \mathrm{v} / \mathrm{v})$. All samples were digested according to the EPA Method 3050B (EPA, 1996) using the Hot Block Digestion System (SISP, DS-360). After digestion all samples were cooled completely and then diluted to $50 \mathrm{~mL}$. Cd concentrations were measured using atomic absorption spectrophotometry (Varian SpectrAA 220Z). In addition, blank and certified reference materials (GSV-2 for plant analysis, GSS-4 for soil analysis, Chinese geological reference materials) were used for quality control.

\section{Soil Enzyme Activities}

Soil dehydrogenase (DHA) activity was assessed by a modification of the method of Singh and Singh (2005). Sieved soil ( $5 \mathrm{~g}$ ) was weighed and mixed with $5 \mathrm{~mL}$ of $0.5 \% 2,3$, 5-triphenyltetrazolium chloride (TTC) solution and incubated for $12 \mathrm{~h}$ at $30^{\circ} \mathrm{C}$ in the dark. After incubation triphenylformazan (TPF), formed by the reduction of TTC, was extracted with three batches of $100 \mathrm{~mL}$ methanol, shaken at $300 \mathrm{rpm}$ for $1 \mathrm{~h}$ and centrifuged at 2,000 $\mathrm{rpm}$ for $5 \mathrm{~min}$. The supernatant was filtered and the concentration of TPF was determined spectrophotometrically at $485 \mathrm{~nm}$. Blanks with TTC omitted were included. All results are expressed as $\mu \mathrm{g} \mathrm{g}^{-1} \mathrm{dw}$.

Fluorescein diacetate (FDA) hydrolysis activity was determined according to Aira and Domínguez (2014). Briefly, $5 \mathrm{~g}$ of sieved soil was incubated for $20 \mathrm{~min}$ at $30^{\circ} \mathrm{C}$ and $200 \mathrm{rpm}$ with $15 \mathrm{~mL}$ of $60 \mathrm{mM}$ potassium dihydrogen phosphate buffer ( $\mathrm{pH} 7.6)$ and $0.2 \mathrm{~mL}$ of FDA stock solution $\left(1000 \mu \mathrm{g} \mathrm{mL}^{-1}\right)$. The reaction was stopped by adding $15 \mathrm{~mL}$ of chloroform/methanol $(1: 1 \mathrm{v} / \mathrm{v})$ and the mixture was gently mixed and centrifuged at $2,000 \mathrm{rpm}$ for $3 \mathrm{~min}$. The supernatant was filtered and read at $490 \mathrm{~nm}$. The results are expressed as $\mu \mathrm{g} \mathrm{g}^{-1} \mathrm{dw}$.

\section{Soil Microbial Biomass C}

The fumigation-extraction method (Vance et al., 1987) was used to determine soil microbial biomass $\mathrm{C}$ according to Beck et al. (1997). Ten grams of sieved soil for chloroform-fumigated and non-fumigated treatments were extracted with $50 \mathrm{~mL}$ of

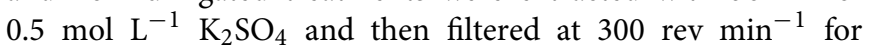
$30 \mathrm{~min}$. Organic $\mathrm{C}$ in the supernatant was measured using an automated TOC Analyzer. Microbial biomass $\mathrm{C}$ was calculated as follows: biomass $\mathrm{C}=\mathrm{Ec} / \mathrm{k}_{\mathrm{EC}}$, where $\mathrm{Ec}=$ (organic $\mathrm{C}$ extracted from fumigated soil) - (organic $\mathrm{C}$ extracted from non-fumigated soil), and $\mathrm{k}_{\mathrm{EC}}$, which was used to convert the measured flush of C to biomass C, was 0.45 (Beck et al., 1997; Yao et al., 2003).

\section{Biolog ${ }^{\circledR}$ EcoPlate Analysis of the Soil Microbial Community}

Soil bacterial functional diversity was assessed as described by Yao et al. (2003). Briefly, $10 \mathrm{~g}$ of sieved soil was added to $100 \mathrm{~mL}$ of sterile water in a $250-\mathrm{mL}$ flask and shaken at $180 \mathrm{rpm}$ for $10 \mathrm{~min}$. Ten-fold serial dilutions were made and $150 \mu \mathrm{L}$ of the final $10^{-3}$ dilution was added to each well of a Biolog ${ }^{\circledR}$ EcoPlate. The plates were incubated at $28^{\circ} \mathrm{C}$ for 7 days and color development in each well was recorded as the absorbance at $590 \mathrm{~nm}$ using a microplate reader (BioTek $\mu$ Quant, Winooski, VT, USA) at regular 12$\mathrm{h}$ intervals. Microbial metabolic activity in each microplate, expressed as the average well-color development (AWCD), was determined as follows: $\mathrm{AWCD}=\Sigma \mathrm{ODi} / 31$, where ODi is the optical density value from each well (Fang et al., 2009). The McIntosh index $(\mathrm{U})$ was calculated as $\mathrm{U}=\sqrt{\left(\sum \mathrm{ni}^{2}\right)}$, where ni refers to the absorbance value (McIntosh, 1967). The Shannon-Weaver index $(\mathrm{H})$ was calculated as $\mathrm{H}=-\Sigma \mathrm{Pi}(\ln \mathrm{Pi})$, where $\mathrm{Pi}$ is the ratio of the activity of each substrate (ODi) to the sum of activities of all substrates ( $\Sigma$ ODi; Zhong et al., 2009).

\section{Quantitative Real-Time PCR Assay}

The abundance of Trichoderma sp. was quantified by real-time PCR (Bio-Rad, Hercules, CA, USA) performed on a Real-Time System and $18 \mathrm{~S}$ rDNA amplifications were performed in a total volume of $20 \mu \mathrm{L}$ containing $2 \mu \mathrm{L}$ of soil microbial DNA, $0.2 \mu \mathrm{L}$ of each of the primers DG (5'-CTGGCATCGATGAAGAACG-3') and DT (5'-ATGCGAGTGTGCAAACTACTG-3') and $10 \mu \mathrm{L}$ 
of SYBR Green I. The qPCR was performed with an initial denaturation and enzyme activation step for $5 \mathrm{~s}$ at $95^{\circ} \mathrm{C}$, followed by 40 cycles of $30 \mathrm{~s}$ at $95^{\circ} \mathrm{C}, 30 \mathrm{~s}$ at $53^{\circ} \mathrm{C}$, and $30 \mathrm{~s}$ at $72^{\circ} \mathrm{C}$ and a final extension performed at $72^{\circ} \mathrm{C}$ for $5 \mathrm{~min}$. Fluorescence measurements were made at the end of each annealing cycle and an additional measuring point at $80^{\circ} \mathrm{C}$ for $1 \mathrm{~s}$ to detect the formation of primer dimers during amplification. A melt curve analysis was performed by raising the temperature from 65 to $95^{\circ} \mathrm{C}$ in $0.2^{\circ} \mathrm{C}$ steps for $1 \mathrm{~s}$ each. The results are expressed as copies $\mathrm{g}^{-1} \mathrm{dw}$.

\section{Data Analysis}

To evaluate the phytoremediation effects of S. plumbizincicola we defined phytoextraction efficiency (\%) as:

$$
\begin{gathered}
\begin{array}{c}
\text { The Cd content accumulated in the plant } \\
\text { shoots after phytoremediation }
\end{array} \\
\hline \text { The initial soil Cd content }
\end{gathered}
$$

and the removal efficiency (\%) as:

The difference of $\mathrm{Cd}$ content in the soil between the beginning and end of phytoremediation

The initial soil Cd content

The pot experiment was performed in quadruplicate and the other experiments in triplicate. All results are presented as the mean $\pm \mathrm{SD}$. Data processing and correlation analysis were performed using MS Excel 2003. The results related to $\mathrm{Cd}$ phytoremediation and soil properties were analyzed by one-way analysis of variance using SigmaPlot 12.5 and all pairwise multiple comparison analyses (Holm-Sidak method) were performed at the $p<0.05$ level.

\section{Results and Discussion}

\section{Cadmium tolerance of $T$. reesei FS10-C}

After incubation at $28^{\circ} \mathrm{C}$ for 7 days the growth of T. reesei FS10$\mathrm{C}$ on solid and in liquid media with different $\mathrm{Cd}$ treatments exhibited similar trends (Figure 1). As the Cd concentration increased, $T$. reesei FS10-C experienced more pronounced growth inhibition. However, FS10-C was still able to grow at a concentration of $300 \mathrm{mg} \mathrm{L}^{-1} \mathrm{Cd}^{2+}$. The growth inhibition ratio of FS10-C is shown in Figure 2 and indicates that FS10-C tolerated high Cd stress.

To better understand the $\mathrm{Cd}$ tolerance of FS10-C its morphological changes under different $\mathrm{Cd}$ treatments were investigated using SEM (Figure 3). The results suggested that there was no significant influence on FS10-C growth in the $10 \mathrm{mg}$ $\mathrm{L}^{-1} \mathrm{Cd}$ treatment compared with the control, although a small irregular fold emerged on the surface of FS10-C mycelia in the $100 \mathrm{mg} \mathrm{L}^{-1} \mathrm{Cd}$ treatment. Furthermore, EDX analysis showed that the peaks of the four nutrient elements $\mathrm{P}, \mathrm{S}, \mathrm{K}$, and $\mathrm{Fe}$ increased (Figure 4).

Cao et al. (2008) found that T. atroviride F6 resisted up to $100 \mathrm{mg} \mathrm{Cd}^{2+} \mathrm{L}^{-1}$ in liquid media. Sahu et al. (2012) indicated

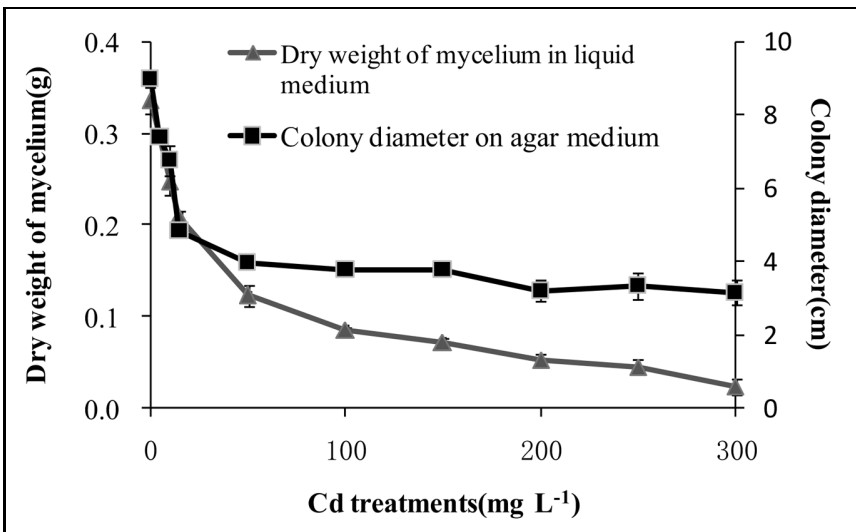

FIGURE 1 | Effect of Cd on the growth of Trichoderma reesei FS10-C. Values are mean $\pm \mathrm{SD}$ of triplicate determinations.

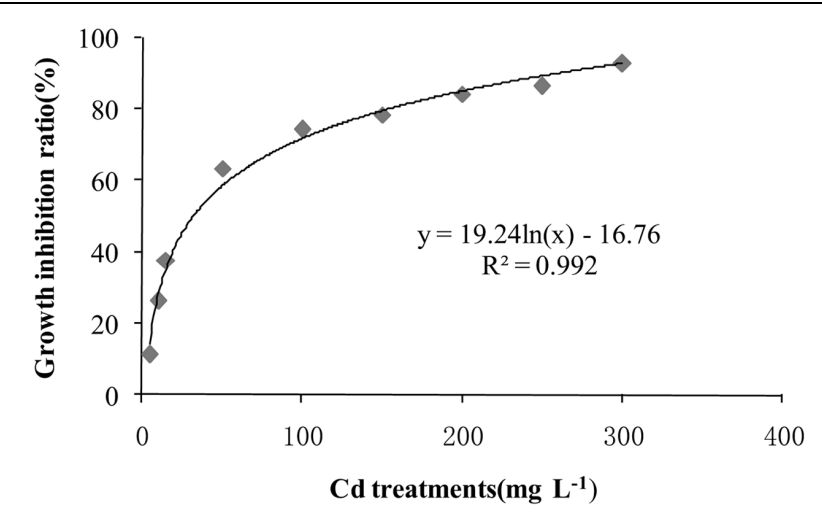

FIGURE 2 | The growth inhibition ratio of T. reesei FS10-C in liquid medium.

that the DW of T. viride mycelia was $0.07 \mathrm{~g}$ in $200 \mathrm{ppm} \mathrm{Cd}$. In addition, Babu et al. (2014a) showed that Trichoderma sp. PDR17 survived in $100 \mathrm{mg} \mathrm{L}^{-1} \mathrm{Cd}$ with $0.9 \mathrm{~g} \mathrm{dw}$. Our results showed that $T$. reesei FS10-C survived in $300 \mathrm{mg} \mathrm{L}^{-1} \mathrm{Cd}$ in both solid and liquid media, indicating that $T$. reesei $\mathrm{FS} 10-\mathrm{C}$ has a high level of Cd tolerance.

\section{Increasing Growth and Cd Uptake by Sedum plumbizincicola When Inoculated with $T$. reesei FS10-C}

Shoot biomass after 120 days is shown in Table 2. The shoot biomass values under the four treatments using inoculation agents were all higher than the control in the following declining sequence: $\mathrm{SP}>\mathrm{SCK}>\mathrm{WP}>\mathrm{WCK}>\mathrm{CK}$. Compared with the control, the fresh shoot weights in the SP and SCK treatments were enhanced by 53 and $30 \%$, respectively $(p<0.05)$, and their corresponding DWs were enhanced by 61 and $35 \%(p<0.05)$. Shoot DW under the WP treatment $\left(12.81 \mathrm{~g} \mathrm{pot}^{-1}\right)$ was also significantly higher $(p<0.05)$ than the control $\left(10.20 \mathrm{~g} \mathrm{pot}^{-1}\right)$ but there was no significant increase in fresh shoot weight under the WP and WCK treatments or shoot DW in the WCK treatment. 


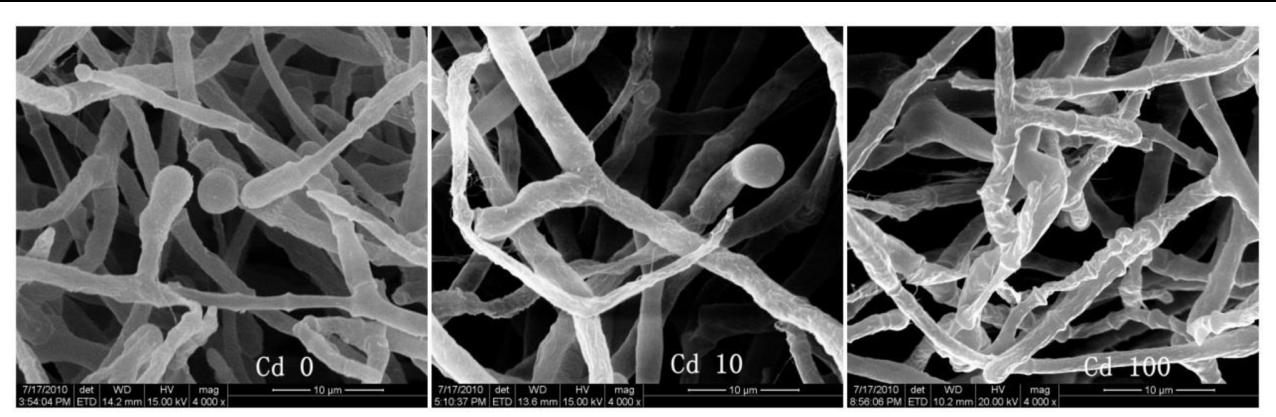

FIGURE 3 | Effect of Cd on the morphology of T. reesei FS10-C.

A

\begin{tabular}{l|ll}
\hline Element & Weight\% & Atomic\% \\
$\mathrm{C} \mathrm{K}$ & 39.08 & 47.24 \\
$\mathrm{O} \mathrm{K}$ & 55.01 & 49.92 \\
$\mathrm{Na} \mathrm{K}$ & 2.36 & 1.49 \\
$\mathrm{Mg} \mathrm{K}$ & 0.20 & 0.12 \\
$\mathrm{P} \mathrm{K}$ & 1.08 & 0.51 \\
$\mathrm{~S} \mathrm{~K}$ & 0.70 & 0.32 \\
$\mathrm{Cl} \mathrm{K}$ & 0.22 & 0.09 \\
$\mathrm{~K} \mathrm{~K}$ & 0.00 & 0.00 \\
$\mathrm{Fe} \mathrm{K}$ & 0.27 & 0.07 \\
$\mathrm{Cu} \mathrm{K}$ & 1.07 & 0.24 \\
& & \\
Totals & 100.00 & \\
\hline
\end{tabular}

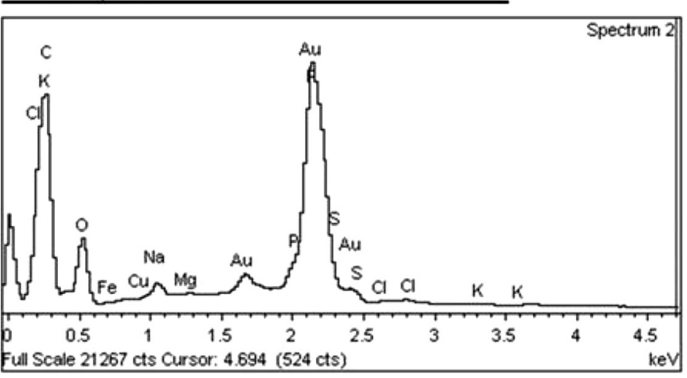

B
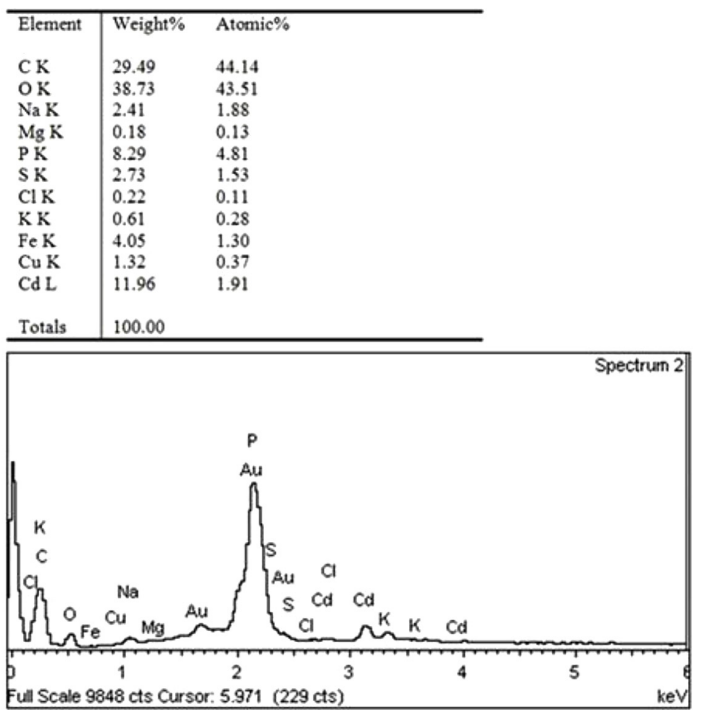

FIGURE 4 | The elemental contents of mycelia under (A) $0 \mathrm{mg} \mathrm{Cd} \mathrm{L}^{-1}$ and (B) $100 \mathrm{mg} \mathrm{Cd} \mathrm{L}^{-1}$ treatments.

TABLE 2 | Effect of inoculation agents on shoot biomass and Cd uptake of Sedum plumbizincicola and phytoremediation.

\begin{tabular}{|c|c|c|c|c|c|c|}
\hline Treatment & $\begin{array}{l}\text { Fresh weight } \\
\left(\operatorname{g~pot}^{-1}\right)\end{array}$ & $\begin{array}{l}\text { Dry weight } \\
\left(\text { g pot }^{-1}\right)\end{array}$ & $\begin{array}{l}\text { Cd uptake } \\
\left(\mathrm{mg} \mathrm{pot}^{-1}\right)\end{array}$ & $\begin{array}{l}\text { Cd conc. in } \\
\text { soil }\left(\mathrm{mg} \mathrm{kg}^{-1}\right)\end{array}$ & $\begin{array}{l}\text { Phytoextraction } \\
\text { efficiency }(\%)\end{array}$ & $\begin{array}{l}\text { Removal } \\
\text { efficiency (\%) }\end{array}$ \\
\hline CK & $123.79 \pm 4.39^{c}$ & $10.20 \pm 0.15^{c}$ & $0.30 \pm 0.04^{b}$ & $0.27 \pm 0.02^{b}$ & $37.24 \pm 4.51^{b}$ & $49.45 \pm 4.43^{b}$ \\
\hline SCK & $160.76 \pm 16.39^{a b}$ & $13.73 \pm 0.97^{b}$ & $0.37 \pm 0.05^{a b}$ & $0.24 \pm 0.01^{a b}$ & $47.12 \pm 6.83^{a b}$ & $54.27 \pm 1.94^{\mathrm{ab}}$ \\
\hline SP & $189.25 \pm 23.35^{a}$ & $16.44 \pm 1.86^{a}$ & $0.46 \pm 0.05^{a}$ & $0.21 \pm 0.01^{a}$ & $58.30 \pm 6.37^{a}$ & $60.50 \pm 1.24^{\mathrm{a}}$ \\
\hline WCK & $131.50 \pm 4.73^{b c}$ & $11.79 \pm 0.59^{b c}$ & $0.33 \pm 0.06^{b}$ & $0.24 \pm 0.03^{a b}$ & $41.02 \pm 7.30^{b}$ & $54.40 \pm 5.73^{a b}$ \\
\hline WP & $141.98 \pm 12.10^{\mathrm{bc}}$ & $12.56 \pm 0.73^{\mathrm{b}}$ & $0.44 \pm 0.03^{a}$ & $0.22 \pm 0.01^{a}$ & $54.84 \pm 3.48^{a}$ & $58.56 \pm 2.39^{a}$ \\
\hline
\end{tabular}

Mean values $( \pm S D)$ followed by different letters with in a column differ significantly at $p<0.05$.

Shoot Cd uptake is also shown in Table 2. Cadmium accumulation under the SP and WP treatments was $0.46 \mathrm{mg}$ pot $^{-1}$ and $0.44 \mathrm{mg}$ pot $^{-1}$ respectively and these values were significantly higher $(p<0.05)$ than the control treatment (0.30 mg pot $\left.{ }^{-1}\right)$. Cadmium uptake under the SCK and WCK treatments did not increase significantly over the control. A significant decline $(p<0.05)$ was observed in all treatments (including the control) compared with the initial soil $\mathrm{Cd}$ content, perhaps attributable to the $\mathrm{Cd}$ accumulation potential of
S. plumbizincicola. The phytoextraction and removal efficiencies of S. plumbizincicola alone (the control treatment) were 37.2 and $49.5 \%$, respectively (Table 2 ). After the addition of inoculation agents the phytoextraction efficiency of S. plumbizincicola increased by $41.0-58.3 \%$ and the removal efficiency increased by $54.3-60.5 \%$ (Table 2 ). In addition, SP and WP treatments with $T$. reesei FS10-C showed greater phytoextraction capabilities and removal efficiencies than SCK and WCK treatments without FS10-C. 
Our results showed that the declining sequence of shoot biomass among all treatments was: $\mathrm{SP}>\mathrm{SCK}>\mathrm{WP}>\mathrm{WCK}>\mathrm{CK}$. It can be concluded that the use of solid fermentation powder as an inoculation agent significantly enhanced $(p<0.05)$ the growth of $S$. plumbizincicola with a distinct advantage over conidium wettable powder. In addition, SP $>$ SCK and WP $>$ WCK showed that the inoculation agents with $T$. reese $\mathrm{FS} 10-\mathrm{C}$ were more effective than inoculation agents without FS10-C, indicating that FS10-C played an important role in promoting the growth of $S$. plumbizincicola. Higher plant biomass under the SCK treatment as compared to the control indicates possible effects of nutrients and Trichoderma secondary metabolites in the inoculation agent for SCK promoting plant growth (Hoyos-Carvajal et al., 2009; Vinale et al., 2009). The sequence of shoot Cd uptake was: $\mathrm{SP}>\mathrm{WP}>\mathrm{SCK}>\mathrm{WCK}>\mathrm{CK}$. Cadmium uptake in the SP and WP treatments was significantly higher than the SCK and WCK treatments $(p<0.05)$, indicating that the inoculation agents with T. reesei FS10-C were more effective in enhancing Cd uptake by S. plumbizincicola than those inoculation agents without FS10-C. In addition, the sequence SP $>$ WP and SCK $>$ WCK showed that higher plant biomass accumulated more $\mathrm{Cd}$.

In general, our study demonstrated that $T$. reesei FS10-C was able to enhance the plant biomass and $\mathrm{Cd}$ accumulation of S. plumbizincicola, especially with an inoculation agent such as solid fermentation powder of FS10-C. Certain other Trichoderma sp. have also been reported to enhance plant growth and Cd uptake under Cd stress. Adams et al. (2007) showed that inoculation with T. harzianum Rifai 1295-22 increased the DW of crack willow and Cd accumulation in the shoots by 39 and $24 \%$, respectively. Babu et al. (2014b) found that inoculation with T. virens PDR-28 increased the DW of maize shoots and Cd accumulation by 56 and 59\%. In our study inoculation with solid fermentation powder of FS10-C increased the DW of S. plumbizincicola shoots by $61 \%$ and shoot Cd accumulation by $53 \%$, representing an enhancement of $\mathrm{Cd}$ phytoremediation. Plant growth promotion by inoculation with FS10-C was mainly attributable to the production of IAA, ACC deaminase and siderophores as well as phosphate solubilization (Gravel et al., 2007; Qi and Zhao, 2013). Qualitative and quantitative analyses of plant growth-promoting traits of FS10-C (Triveni et al., 2013; Kotasthane et al., 2015) have been carried out. The results showed that FS10-C had the ability to produce ACC deaminase and siderophores and to solubilize phosphate (Supplementary Figures S1 and S2; average siderophore production was 68\%) and this agrees with the findings of Babu et al. (2014b,c). Increased $\mathrm{Cd}$ uptake induced by FS10-C might be attributed to the successful colonization of FS10-C both promoting plant growth to accumulate more $\mathrm{Cd}$ and enhancing $\mathrm{Cd}$ phytoextraction by altering the solubility, availability and transport of Cd (Song et al., 2015).

\section{Changes in Soil pH and Available P}

After 120 days there was a clear decline $(p<0.05)$ in soil available $\mathrm{P}$ concentration in all treatments compared with the initial value (8.6 $\left.\mathrm{mg} \mathrm{kg}^{-1}\right)$, but there was no significant difference in soil $\mathrm{pH}$ (Table 3). Compared with the control the $\mathrm{pH}$ under the SP
TABLE 3 | Soil pH and available P concentration after phytoremediation for 120 days.

\begin{tabular}{lll}
\hline Treatment & $\mathbf{p H}$ & Available $\mathbf{P}\left(\mathbf{m g ~ k g}^{\mathbf{- 1}}\right)$ \\
\hline CK & $4.63 \pm 0.03^{\mathrm{bc}}$ & $3.60 \pm 0.11^{\mathrm{c}}$ \\
SCK & $4.84 \pm 0.14^{\mathrm{a}}$ & $6.15 \pm 0.46^{\mathrm{b}}$ \\
SP & $4.80 \pm 0.06^{\mathrm{ab}}$ & $7.43 \pm 0.40^{\mathrm{a}}$ \\
WCK & $4.68 \pm 0.09^{\mathrm{ac}}$ & $2.64 \pm 0.19^{\mathrm{d}}$ \\
WP & $4.55 \pm 0.06^{\mathrm{c}}$ & $3.25 \pm 0.09^{\mathrm{c}}$ \\
\hline
\end{tabular}

Mean values $( \pm S D)$ followed by different letters with in a column differ significantly at $p<0.05$.

treatment increased significantly $(p<0.05)$. Soil available $\mathrm{P}$ under the SP and SCK treatments increased substantially $(p<0.05)$ by 107 and $71 \%$, respectively, compared with the control.

Soil available $\mathrm{P}$ under both SP and SCK treatments was significantly higher than the control $(p<0.05)$, indicating that T. reesei FS10-C played important role in enhancing nutrient release into the soil. Furthermore, more soil available $\mathrm{P}$ under the SP treatment than SCK showed that the role of FS10-C was more prominent. This was likely due to the phosphate solubilizing capacity of FS10-C. However, the soil available P values under both WP and WCK treatments were lower than the control. This might be attributable to the spore content of FS10-C being quite small in the inoculation agent of the WP treatment and the inoculation agents in both WP and WCP treatments being added by foliar spray which would have made little contribution to the solubilization of $\mathrm{P}$ in the soil. The overall decline in soil available $\mathrm{P}$ under all treatments compared with the initial value might be attributable to plant nutrient uptake as available $\mathrm{P}$ was positively related to plant fresh and DWs with $R^{2}$ values of 0.86 and 0.72 , respectively. In addition, our results showed that soil $\mathrm{pH}$ values also increased under both SP and SCK treatments in addition to soil available $\mathrm{P}$, which differed with the earlier conclusion that soil available $\mathrm{P}$ was negatively related to soil $\mathrm{pH}$ (Deng et al., 2012; Babu et al., 2014c). This was likely due to the soil $\mathrm{pH}$ value being neutralized after the addition of the inoculation agent.

\section{Enhancement of Soil Microbial Activities by Inoculation Agents}

Microbial biomass C, DHA and FDA hydrolysis activities under the four treatments with the addition of inoculation agents were enhanced to different degrees after phytoremediation (Table 4). The highest increase in soil microbial biomass C $(145 \%, p<0.05)$ was observed under the SP treatment, followed by SCK and WP treatments with increases of 62 and 62\%, respectively $(p<0.05)$. Similarly, the highest DHA activity was found under the SP treatment, followed by SCK, WP and WCK, and all exhibited significantly higher levels than the control with increases of $86,56,49$, and $20 \%(p<0.05)$, respectively. In terms of FDA hydrolysis activity, the four treatments with the addition of inoculation agents were significantly higher than the control, with increases of $69,69,49$, and $34 \%(p<0.05)$. Furthermore, the treatments involving inoculation with conidium wettable powder with or without $T$. reesei FS10-C clearly demonstrated greater ability to increase FDA hydrolysis activity than those inoculated 
TABLE 4 | Microbial biomass $C$ and soil enzyme activities after phytoremediation for 120 days.

\begin{tabular}{|c|c|c|c|}
\hline Treatment & $\begin{array}{l}\text { Microbial biomass C } \\
\mu \mathrm{g} \mathrm{g}^{-1}\end{array}$ & $\begin{array}{l}\text { DHA activity } \\
\mu \mathrm{g} \mathrm{g}^{-1} \mathrm{dw}\end{array}$ & $\begin{array}{l}\text { FDA hydrolysis activity } \\
\mu \mathrm{g} \mathrm{g}^{-1} \mathrm{dw} \times 20 \mathrm{~min}\end{array}$ \\
\hline $\mathrm{CK}$ & $217.21 \pm 48.96^{c}$ & $55.82 \pm 3.05^{d}$ & $17.60 \pm 2.78^{c}$ \\
\hline SCK & $340.15 \pm 44.69^{b}$ & $86.67 \pm 4.05^{\mathrm{b}}$ & $23.18 \pm 0.39^{b}$ \\
\hline $\mathrm{SP}$ & $522.51 \pm 73.52^{a}$ & $103.80 \pm 5.23^{a}$ & $25.83 \pm 3.14^{b}$ \\
\hline WCK & $246.08 \pm 12.20^{c}$ & $66.98 \pm 2.07^{c}$ & $29.27 \pm 2.04^{a}$ \\
\hline WP & $341.71 \pm 26.26^{b}$ & $82.71 \pm 1.97^{b}$ & $29.28 \pm 1.36^{a}$ \\
\hline
\end{tabular}

Mean values $( \pm S D)$ followed by different letters with in a column differ significantly at $p<0.05$.

with solid fermentation powder with or without $T$. reesei FS10-C.

The maintenance of soil fertility depends on the microbial biomass and its activities which are of primary importance in nutrient cycling and ecosystem sustainability, and microbial biomass and activities are sensitive to changes in soil HM content (Giller et al., 1998). One of the soil microbiological parameters, microbial biomass $\mathrm{C}$, is considered to be a sensitive indicator of HM toxicity and soil quality (Yao et al., 2003). Our data suggested that all inoculation agents with or without T. reesei FS10-C, particularly the solid fermentation powder of T. reesei FS10-C, increased microbial biomass C. In addition, soil DHA activity based on the metabolic state of the soil biota (Araujo et al., 2015) is also used to assess soil health (Gil-Sotres et al., 2005). Our results showed that all inoculation agents tested enhanced DHA activity, indicating that the general activities of soil microbes were enhanced. FDA hydrolysis activity is also a good indicator of soil health in the presence of metal contaminants (Frølund et al., 1995; Gil-Sotres et al., 2005). All inoculation agents increased FDA hydrolysis activity, indicating that the metabolism of soil microbes was promoted, thus resulting in the enhanced microbial activities.

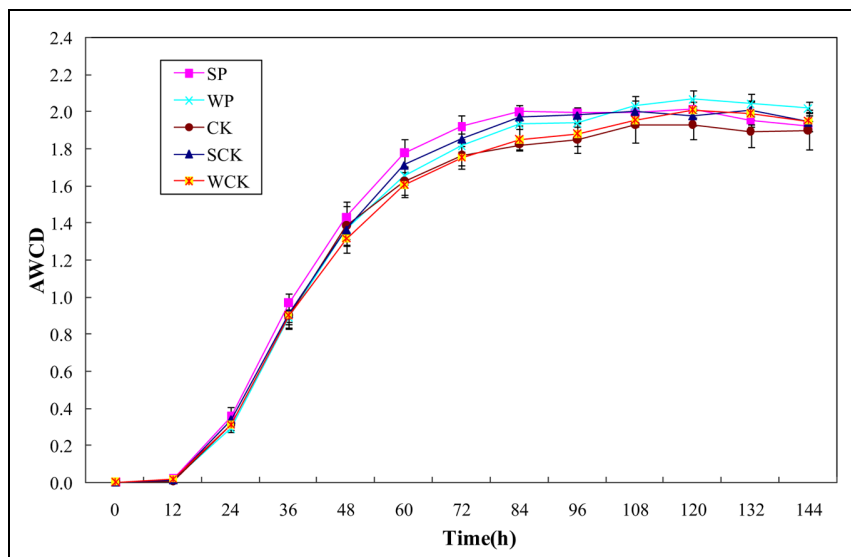

FIGURE 5 | Average well color development (AWCD) values of microbial communities under the different treatments. Values are means \pm SD of triplicate measurements.

\section{Changes in Microbial Community Functional Diversity after Phytoremediation}

Changes in AWCD reflecting the oxidative catabolism of the microbial community over time are shown in Figure 5. It is clear that AWCD values for all treatments initially increased rapidly until $84 \mathrm{~h}$ and then tended to slow down. The average AWCD values for SP, SCK, WP, and WCK treatments were 2.00, $1.97,1.93$, and 1.85 respectively. SP, SCK and WP treatments were significantly higher than the control $(1.82, p<0.05)$ but WCK treatment did not significantly increase compared with the control. The Shannon-Weaver index and McIntosh index are used to indicate microbial community richness (Fang et al., 2009) and evenness (McIntosh, 1967), respectively. The data in Table 5 indicate that there was no significant difference between the values of Shannon-Weaver index under all treatments. The values of the McIntosh index under all treatments reached a level of 10.68-11.61 (Table 5) and the values under SP, SCK, and WP treatments were significantly higher than that in the control $(p<0.05)$.

Microbial community structure is also considered to be a biological indicator of HM stress (Doelman et al., 1994). The Biolog ${ }^{\circledR}$ EcoPlate method combined with other analyses such as the diversity indices has been recommended to evaluate whole soil microbial community functional diversity (Ros et al., 2008). Our data showed that

TABLE 5 | Shannon-Weaver index $(H)$ and Mclntosh index (U) based on community level physiological profiles detected using a Biolog EcoPlate.

\begin{tabular}{lll}
\hline Treatment & $\mathbf{H}(\mathbf{8 4} \mathbf{h})$ & $\mathbf{U}$ \\
\hline CK & $3.371 \pm 0.021^{\mathrm{a}}$ & $10.681 \pm 0.054^{\mathrm{b}}$ \\
SCK & $3.381 \pm 0.014^{\mathrm{a}}$ & $11.435 \pm 0.243^{\mathrm{a}}$ \\
SP & $3.374 \pm 0.009^{\mathrm{a}}$ & $11.607 \pm 0.519^{\mathrm{a}}$ \\
WCK & $3.364 \pm 0.012^{\mathrm{a}}$ & $10.822 \pm 0.259^{\mathrm{b}}$ \\
WP & $3.362 \pm 0.024^{\mathrm{a}}$ & $11.310 \pm 0.262^{\mathrm{a}}$
\end{tabular}

Mean values $( \pm S D$ ) followed by different letters within a column differ significantly at $p<0.05$.

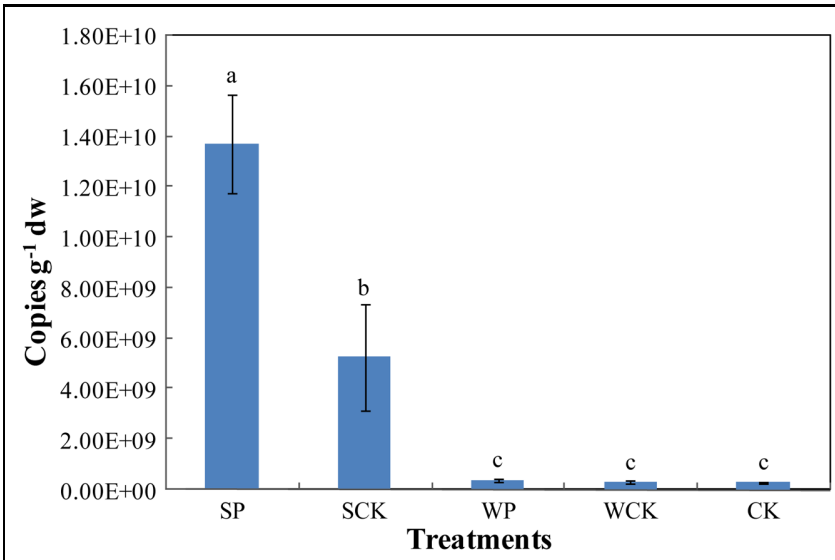

FIGURE 6 | The gene copy numbers of soil Trichoderma sp. under the different treatments. Values are means $\pm S D$ of triplicate measurements. 
the evenness of the soil microbial community was enhanced by all inoculation agents but no significant variation in richness. It was likely due to the low levels of Cd contamination in the soil and the similar experimental conditions in each of the treatments. A similar study also indicated that differences in flora could not be distinguished sensitively by the diversity indices when the experimental conditions did not differ significantly between different treatments (Drenovsky et al., 2008). In addition, the AWCD values were also enhanced by all inoculation agents and found to be closely correlated with microbial biomass $\mathrm{C}\left(R^{2}=0.81\right)$, indicating that microbial biomass and metabolic activity were both enhanced by the addition of the inoculation agents. High concentrations of HMs affect the functional diversity of soil microbial community, resulting in a decline in soil quality (Chander and Brookes, 1993). Our results demonstrated that the soil microbial community might be protected and even enhanced by phytoremediation using S. plumbizincicola with all tested inoculation agents, particularly the solid fermentation powder of $T$. reesei FS10-C.

\section{Trichoderma Colonization Ability of Solid Fermentation Powder of T. reesei FS10-C}

The abundance of Trichoderma sp. was estimated via the realtime quantification of its rDNA gene copy numbers (Figure 6). The results show that the abundance of Trichoderma sp. under SP treatment reached its highest level of $1.37 \times 10^{10}$ copies $\mathrm{g}^{-1} \mathrm{dw}$ after phytoremediation, followed by $5.26 \times 10^{9}$ copies $\mathrm{g}^{-1} \mathrm{dw}$ under the SCK treatment. Both were significantly higher $(p<0.05)$ than the other three treatments (WP: $3.94 \times 10^{8}$ copies $\mathrm{g}^{-1} \mathrm{dw}$, WCK: $2.92 \times 10^{8}$ copies $\mathrm{g}^{-1} \mathrm{dw}$, CK: $2.98 \times 10^{8}$ copies $\mathrm{g}^{-1} \mathrm{dw}$ ), which were not significantly different from each other.

It is clear that the SCK treatment resulted in a high Trichoderma gene abundance, suggesting that the organic substance present in the inoculation agent supplied nutrients and promoted the growth of indigenous Trichoderma in the soil. In addition, the Trichoderma gene abundance under the SP treatment was significantly higher $(p<0.05)$ than SCK, indicating that FS10-C helped Trichoderma sp. to be the most advantaged flora in the soil and enhanced the colonization ability of Trichoderma. The Trichoderma gene copies were low in the WP and WCK treatments. Possible explanations for this are restriction of the formation of advantageous flora by the decreased FS10-C spore content and the addition of the two inoculation agents (foliar spray) being adverse to the rhizosphere gene expression of FS10-C.

Babu et al. (2014b) indicated that plant growth and HM uptake enhancement were attributable to the successful colonization of $T$. virens PDR-28 in soil. Our results showed

\section{References}

Adams, P., De-Leij, F. A., and Lynch, J. M. (2007). Trichoderma harzianum Rifai 1295-22 mediates growth promotion of crack willow (Salix fragilis) saplings in both clean and metal-contaminated soil. Microb. Ecol. 54, 306-313. doi: 10.1007/s00248-006-9203-0 that Trichoderma gene abundance was positively related to plant DW, Cd uptake, available P, microbial biomass $\mathrm{C}$ and DHA activity $\left(R^{2}\right.$ values were $0.84,0.41,0.88,0.85$, and 0.72 , respectively). Thus, we supposed that the successful colonization of $T$. reesei FS10-C was contributed to the enhancement of plant growth, $\mathrm{Cd}$ uptake, nutrient release, microbial biomass and activities. This also indicated that T. reesei FS10-C was a good candidate for the enhancement of $\mathrm{Cd}$ phytoremediation.

\section{Conclusion}

To our knowledge this is the first report demonstrating the potential of $T$. reesei FS10-C to promote plant growth and the Cd removal capacity of $S$. plumbizincicola grown in Cdcontaminated soil. Our results showed that all the inoculation agents tested were able to increase plant biomass and Cd uptake with the simultaneous inoculation of FS10-C compared with inoculation without FS10-C thereby increasing the efficiency of phytoremediation by $S$. plumbizincicola. In addition, nutrition release and microbial activities were promoted, particularly by the solid fermentation powder of FS10-C, indicating an enhancement of soil fertility after phytoremediation. We also found that Trichoderma colonization ability played an important role in enhancing plant growth, Cd removal and soil fertility. Solid fermentation powder of $T$. reesei FS10C showed the greatest Trichoderma colonization ability and thus the greatest potential for use as an inoculation agent to enhance Cd phytoremediation. However, field experiments need to be conducted to further verify the practical effects of the application of solid fermentation powder of FS10-C under field conditions.

\section{Acknowledgments}

This work was jointly supported by the Science and Technology Service Network Initiative (Project KFJ-EW-ZY-005) and the High Technology Research Development Program of the People's Republic of China (Projects 2012AA06A204 and 2007AA061001). We thank Professor Longhua $\mathrm{Wu}$ and his research group at Nanjing Institute of Soil Science for providing the hyperaccumulator seedlings.

\section{Supplementary Material}

The Supplementary Material for this article can be found online at: http://journal.frontiersin.org/article/10.3389/fpls. 2015.00438/abstract

Aira, M., and Domínguez, J. (2014). Changes in nutrient pools, microbial biomass and microbial activity in soils after transit through the gut of three endogeic earthworm species of the genus Postandrilus Qui and Bouché, 1998. J. Soils Sediments 14, 1335-1340. doi: 10.1007/s11368-014-0889-1

Araujo, A. S. F., Miranda, A. R. L., Oliveira, M. L. J., Santos, V. M., Nunes, L. A. P. L., and Melo, W. J. (2015). Soil microbial properties after 5 years of 
consecutive amendment with composted tannery sludge. Environ. Monit. Assess 187:4153. doi: 10.1007/S10661-014-4153-3

Babu, A. G., Shea, P. J., and Oh, B.-T. (2014a). Trichoderma sp. PDR1-7 promotes Pinus sylvestris reforestation of lead-contaminated mine tailing sites. Sci. Total Environ. 476-477:561-567. doi: 10.1016/j.scitotenv.2013. 12.119

Babu, A. G., Shim, J., Bang, K.-S., Shea, P. J., and Oh, B.-T. (2014b). Trichoderma virens PDR-28: a heavy metal-tolerant and plant growthpromoting fungus for remediation and bioenergy crop production on mine tailing soil. J. Environ. Manage. 132, 129-134. doi: 10.1016/j.jenvman.2013. 10.009

Babu, A. G., Shim, J., Shea, P. J., and Oh, B.-T. (2014c). Penicillium aculeatum PDR4 and Trichoderma sp. PDR-16 promote phytoremediation of mine tailing soil and bioenergy production with sorghum-sudangrass. Ecol. Eng. 69, 186-191. doi: 10.1016/j.ecoleng.2014.03.055

Bareen, F. E., Shafiq, M., and Jamil, S. (2012). Role of plant growth regulators and a saprobic fungus in enhancement of metal phytoextraction potential and stress alleviation in pearl millet. J. Hazard. Mater. 237-238:186-193. doi: 10.1016/j.jhazmat.2012.08.033

Beck, T., Joergensen, R. G., Kandeler, E., Makeschin, F., Nuss, E., Oberholzer, H. R., et al. (1997). An inter-laboratory comparison of ten different ways of measuring soil microbial biomass C. Soil Biol. Biochem. 29, 1023-1032. doi: 10.1016/s0038-0717(97)00030-8

Cao, L. X., Jiang, M., Zeng, Z. R., Du, A. X., Tan, H. M., and Liu, Y. H. (2008). Trichoderma atroviride F6 improves phytoextraction efficiency of mustard (Brassica juncea (L.) Coss. var. foliosa Bailey) in $\mathrm{Cd}$, Ni contaminated soils. Chemosphere 71, 1769-1773. doi: 10.1016/j.chemosphere.2008. 01.066

Chander, K., and Brookes, P. C. (1993). Residual effects of zinc, copper and nickel in sewage sludge on microbial biomass in a sandy loam. Soil Biol. Biochem. 25, 1231-1239. doi: 10.1016/0038-0717(93)90219-2

De Freitas Lima, A., de-Moura, G. F., de-Lima, M. A. B., de-Souza, P. M., daSilva, C. A. A., De Campos Takaki, G. M., et al. (2011). Role of the morphology and polyphosphate in Trichoderma harzianum related to cadmium removal. Molecules 16, 2486-2500. doi: 10.3390/molecules16032486

Deng, X. H., Chai, L. Y., Yang, Z. H., Tang, C. J., Tong, H. X., and Yuan, P. F. (2012). Bioleaching of heavy metals from a contaminated soil using indigenous Penicillium chrysogenum strain F1. J. Hazard. Mater. 233-234:25-32. doi: 10.1016/j.jhazmat.2012.06.054

Doelman, P., Jansen, E., Michels, M., and Vantil, M. (1994). Effects of heavy-metals in soil on microbial diversity and activity as shown by the sensitivity-resistance index, an ecologically relevant parameter. Biol. Fertil. Soils 17, 177-184. doi: 10.1007/BF00336319

Drenovsky, R. E., Feris, K. P., Batten, K. M., and Hristova, K. (2008). New and current microbiological tools for ecosystem ecologists: towards a goal of linking structure and function. Am. Midl. Nat. 160, 140-159. doi: 10.1674/00030031(2008)160[140:nacmtf]2.0.co;2

EPA. (1996). "Method 3050B. Acid digestion of sediments, sludges, and soils. Method 3050B," in Test Methods for Evaluating Solid Wastes: Physical/Chemical Methods, EPA SW-846 (Washington, DC: Office of Solid Waste and Emergency Response, U.S. Environmental Protection Agency).

Fang, H., Yu, Y. L., Chu, X. Q., Wang, X. G., Yang, X. E., and Yu, J. Q. (2009). Degradation of chlorpyrifos in laboratory soil and its impact on soil microbial functional diversity. J. Environ. Sci. 21, 380-386. doi: 10.1016/s10010742(08)62280-9

Frølund, B., Griebe, T., and Nielsen, P. H. (1995). Enzymatic activity in the activated-sludge floc matrix. Appl. Microbiol. Biotechnol. 43, 755-761. doi: $10.1007 / \mathrm{s} 002530050481$

Gil-Sotres, F., Trasar-Cepeda, C., Leirós, M. C., and Seoane, S. (2005). Different approaches to evaluating soil quality using biochemical properties. Soil Biol. Biochem. 37, 877-887. doi: 10.1016/j.soilbio.2004.10.003

Giller, K. E., Witter, E., and Mcgrath, S. P. (1998). Toxicity of heavy metals to microorganisms and microbial processes in agricultural soils: a review. Soil Biol. Biochem. 30, 1389-1414. doi: 10.1016/s0038-0717(97)00270-8

Gravel, V., Antoun, H., and Tweddell, R. J. (2007). Growth stimulation and fruit yield improvement of greenhouse tomato plants by inoculation with Pseudomonas putida or Trichoderma atroviride: possible role of indole acetic acid (IAA). Soil Biol. Biochem. 39, 1968-1977. doi: 10.1016/j.soilbio.2007.02.015
Harman, G. E., Howell, C. R., Viterbo, A., Chet, I., and Lorito, M. (2004). Trichoderma species - Opportunistic, avirulent plant symbionts. Nat. Rev. Microbiol. 2, 43-56. doi: 10.1038/nrmicro797

Hoyos-Carvajal, L., Orduz, S., and Bissett, J. (2009). Growth stimulation in bean (Phaseolus vulgaris L.) by Trichoderma. Biol. Control 51, 409-416. doi: 10.1016/j.biocontrol.2009.07.018

Hu, P. J., Yin, Y.-G., Ishikawa, S., Suzui, N., Kawachi, N., Fujimaki, S., et al. (2013). Nitrate facilitates cadmium uptake, transport and accumulation in the hyperaccumulator Sedum plumbizincicola. 20, 6306-6316. doi: 10.1007/s11356013-1680-3

Hughes, M. R., Bailer, A. J., and Denton, D. L. (2001). Toxicant- and response-specific comparisons of statistical methods for estimating effective concentrations. Environ. Toxicol. Chem. 20, 1374-1380. doi 10.1897/15515028(2001) $020<1374:$ Tarsco $>2.0$. Co; 2

Kexiang, G., Xiaoguang, L., Yonghong, L., Tianbo, Z., and Shuliang, W. (2002). Potential of Trichoderma harzianum and T-atroviride to control Botryosphaeria berengeriana f. sp piricola, the cause of apple ring rot. J. Phytopathol. 150, 271-276. doi: 10.1046/j.1439-0434.2002.00754.x

Kotasthane, A., Agrawal, T., Kushwah, R., and Rahatkar, O. V. (2015). In-vitro antagonism of Trichoderma spp. against Sclerotium rolfsii and Rhizoctonia solani and their response towards growth of cucumber, bottle gourd and bitter gourd. Eur. J. Plant Pathol. 141, 523-543. doi: 10.1007/s10658-0140560-0

Li, J. T., Liao, B., Zhu, R., Dai, Z. Y., Lan, C. Y., and Shu, W. S. (2011). Characteristics of $\mathrm{Cd}$ uptake, translocation and accumulation in a novel Cd-accumulating tree, star fruit (Averrhoa carambola L., Oxalidaceae). Environ. Exp.Bot. 71, 352-358. doi: 10.1016/j.envexpbot.2011. 02.001

McIntosh, R. P. (1967). An index of diversity and relation of certain concepts to diversity. Ecology 48, 392-404. doi: 10.2307/1932674

Olsen, S. R., Cole, C. V., Watanabe, F. S., and Dean, L. A. (1954). Estimation of Available Phosphorus in Soils by Extraction with Sodium Bicarbonate. Washington, DC: U.S. Government Printing Office.

Qi, W. Z., and Zhao, L. (2013). Study of the siderophore-producing Trichoderma asperellum Q1 on cucumber growth promotion under salt stress. J. Basic Microbiol. 53, 355-364. doi: 10.1002/jobm.201200031

Rajkumar, M., Sandhya, S., Prasad, M. N. V., and Freitas, H. (2012). Perspectives of plant-associated microbes in heavy metal phytoremediation. Biotechnol. Adv. 30, 1562-1574. doi: 10.1016/j.biotechadv.2012.04.011

Ros, M., Goberna, M., Pascual, J. A., Klammer, S., and Insam, H. (2008). 16S rDNA analysis reveals low microbial diversity in community level physiological profile assays. J. Microbiol. Methods 72, 221-226. doi: 10.1016/j.mimet.2008. 01.003

Sahu, A., Mandal, A., Thakur, J., Manna, M. C., and Rao, A. S. (2012). Exploring bioaccumulation efficacy of Trichoderma viride: an alternative bioremediation of cadmium and lead. Natl. Acad. Sci. Lett. 35, 299-302. doi: 10.1007/s40009012-0056-4

Shin, M.-N., Shim, J., You, Y., Myung, H., Bang, K.-S., Cho, M., et al. (2012). Characterization of lead resistant endophytic Bacillus sp MN3-4 and its potential for promoting lead accumulation in metal hyperaccumulator Alnus firma. J. Hazard. Mater. 199, 314-320. doi: 10.1016/j.jhazmat.2011.11.010

Singh, J., and Singh, D. K. (2005). Dehydrogenase and phosphomonoesterase activities in groundnut (Arachis hypogaea L.) field after diazinon, imidacloprid and lindane treatments. Chemosphere 60, 32-42. doi: 10.1016/j.chemosphere.2004.11.096

Song, N. N., Ma, Y. B., Zhao, Y. J., and Tang, S. R. (2015). Elevated ambient carbon dioxide and Trichoderma inoculum could enhance cadmium uptake of Lolium perenne explained by changes of soil $\mathrm{pH}$, cadmium availability and microbial biomass. Appl. Soil Ecol. 85, 56-64. doi: 10.1016/j.apsoil.2014.09.007

Tapia, E., Montes, C., Rebufel, P., Paradela, A., Prieto, H., and Arenas, G. (2011). Expression of an optimized Argopecten purpuratus antimicrobial peptide in E. coli and evaluation of the purified recombinant protein by in vitro challenges against important plant fungi. Peptides 32, 1909-1916. doi: 10.1016/j.peptides.2011.07.007

Triveni, S., Prasanna, R., Shukla, L., and Saxena, A. K. (2013). Evaluating the biochemical traits of novel Trichoderma-based biofilms for use as plant growthpromoting inoculants. Ann. Microbiol. 63, 1147-1156. doi: 10.1007/s13213012-0573-x 
Vance, E. D., Brookes, P. C., and Jenkinson, D. S. (1987). An extraction method for measuring soil microbial biomass-C. Soil Biol. Biochem. 19, 703-707. doi: 10.1016/0038-0717(87)90052-6

Vinale, F., Flematti, G., Sivasithamparam, K., Lorito, M., Marra, R., Skelton, B. W., et al. (2009). Harzianic acid, an antifungal and plant growth promoting metabolite from Trichoderma harzianum. J. Nat. Prod. 72, 2032-2035. doi: 10.1021/Np900548p

Williams, J., Clarkson, J. M., Mills, P. R., and Cooper, R. M. (2003). Saprotrophic and mycoparasitic components of aggressiveness of Trichoderma harzianum groups toward the commercial mushroom Agaricus bisporus. Appl. Environ. Microbiol. 69, 4192-4199. doi: 10.1128/aem.69.7.4192-419 9.2003

Wu, L. H., Li, Z., Akahane, I., Liu, L., Han, C. L., Makino, T., et al. (2012). Effects of organic amendments on $\mathrm{Cd}, \mathrm{Zn}$ and $\mathrm{Cu}$ bioavailability in soil with repeated phytoremediation by Sedum plumbizincicola. Int. J. Phytoremediat. 14, 1024-1038. doi: 10.1080/15226514.2011.64 9436

Yao, H. Y., Xu, J. M., and Huang, C. Y. (2003). Substrate utilization pattern, biomass and activity of microbial communities in a sequence of heavy metalpolluted paddy soils. Geoderma 115, 139-148. doi: 10.1016/s0016-7061(03) 00083-1
Zafar, S., Aqil, F., and Ahmad, Q. (2007). Metal tolerance and biosorption potential of filamentous fungi isolated from metal contaminated agricultural soil. Bioresour. Technol. 98, 2557-2561. doi: 10.1016/j.biortech.2006.09.051

Zhong, W. H., Gu, T., Wang, W., Zhang, B., Lin, X. G., Huang, Q. R., et al. (2009). The effects of mineral fertilizer and organic manure on soil microbial community and diversity. Plant Soil 326, 511-522. doi: 10.1007/s11104-0099988-y

Conflict of Interest Statement: The Guest Associate Editor Ying Ma declares that, despite having collaborated with the authors Ying Teng, Yongming Luo and Zhengao Li, the review process was handled objectively. The authors declare that the research was conducted in the absence of any commercial or financial relationships that could be construed as a potential conflict of interest.

Copyright (C) 2015 Teng, Luo, Ma, Zhu, Ren, Luo, Christie and Li. This is an openaccess article distributed under the terms of the Creative Commons Attribution License (CC BY). The use, distribution or reproduction in other forums is permitted, provided the original author(s) or licensor are credited and that the original publication in this journal is cited, in accordance with accepted academic practice. No use, distribution or reproduction is permitted which does not comply with these terms. 